\title{
CANADA'S EXPERIENCE IN DEVELOPING A NATIONAL DISASTER MITIGATION STRATEGY: A DELIBERATIVE DIALOGUE APPROACH
}

\author{
VALERIAH HWACHA \\ Public Safety and Emergency Preparedness Canada (PSEPC), Jackson Building, 122 Bank Street, \\ Ottawa, Ontario, K1A OW6 \\ (Tel: (613) 991-3546, Fax: (613) 954-3722; E-mail:Valeriah.Hwacha@psepc-sppec.gc.ca)
}

(Received 2 December 2003; accepted in final form 4 March 2004)

\begin{abstract}
Canada is vulnerable to a wide range of natural and human-induced disasters. Recent experience with major natural disasters demonstrated that more needs to be done to protect Canadians from the impacts of future disasters. The Government of Canada, through the Department of Public Safety and Emergency Preparedness Canada, has conducted consultations with provinces, territories and stakeholders to develop a national disaster mitigation strategy (NDMS) aimed at enhancing Canada's capacity to prevent disasters before they occur and promoting the development of disasterresilient communities. This paper provides an overview of Canada's emergency management and hazards context. It reports on the preliminary findings of consultations with stakeholders and evaluates the usefulness of the deliberative dialogue methodology that was used to facilitate the consultations. Examples that are illustrative of recent Canadian efforts on disaster mitigation and the challenges respecting the development and future implementation of a NDMS are also discussed.
\end{abstract}

Keywords: consultations, deliberative dialogue, disasters, emergency management, hazards, mitigation, prevention, risk reduction

\section{Introduction}

One of the key roles and priorities for the Government of Canada is to promote quality of life for, and ensure the safety and security of, individual citizens and their communities. A new Department of Public Safety and Emergency Preparedness Canada (PSEPC) that incorporates the former Office of Critical Infrastructure Protection and Emergency Preparedness (OCIPEP 2002a; 2002b), the Department of the Solicitor General of Canada, the Canada Border Services Agency, the Crime Prevention Secretariat of the Department of Justice and enforcement components of Citizenship and Immigration Canada and the Canadian Food Inspection Agency, was created by the Prime Minister of Canada in December of 2003. In assuming the responsibilities of the former OCIPEP, PSEPC is now the Government of Canada's department with lead responsibility for integrating national security and emergency preparedness partly through coordinating responses to national emergencies and protecting Canada's national critical infrastructure. This includes activities that reduce disaster vulnerability, support emergency preparedness and response efforts, and supplement disaster recovery, in part through financial assistance to provincial and territorial governments after disasters. Other federal government departments 
play important roles to mitigate potential hazards or their consequences based on delegated authorities and departmental expertise.

Canada is fortunate that relatively few lives have been lost due to natural disasters, but the costs related to personal property and public infrastructure damage are significant. The Disaster Financial Assistance Arrangements (DFAA), established in 1970, are the primary mechanism by which the Government of Canada provides assistance to Canadians affected by natural disaster through ex post facto payments to provincial and territorial governments. Since 1996, Canada has experienced a significant escalation in DFAA costs. The physical devastation and economic losses resulting from the Saguenay River flood (1996), the Red River flood (1997) and the eastern Canada ice storm (1998) exposed the susceptibility of Canadians to major natural hazards. Together, these events affected approximately $20 \%$ of the Canadian population and cost the Canadian government an average of \$366 million each in disaster financial assistance payments. Notably, prior to 1996, the Canadian government's disaster assistance costs per incident did not exceed \$30 million.

Mitigation receives comparatively less attention than preparedness, response or recovery, making it the least developed component of Canada's emergency management system. The three major natural disasters mentioned above prompted the Government of Canada to embark on a major initiative to develop a NDMS and consider explicitly the need for pre-event mitigation measures to limit Canada's vulnerability to disasters. A NDMS would enhance Canada's capacity to implement measures that reduce risk, limit social disruption and contain the economic costs that result from disasters. It would replace a piecemeal approach with a proactive and systematic coordination of mitigative activities that foster the development of disaster-resilient communities.

In 1998, and again in 2002, the Canadian government undertook a collaborative and multidisciplinary consultation with stakeholders that focused attention on disaster mitigation as a vital component of comprehensive emergency management. This paper provides an overview of Canada's natural hazards context and disaster trends, descibes the experience of the deliberative dialogue consultative process that was utilized to facilitate the 2002 NDMS consultations and reports on the progress that Canada has made to advance the concept and practice of disaster mitigation.

\section{Canadian Natural Hazards Context}

Canada's immense size, varied climate and extensive geography expose it to numerous natural hazards. The geologic characteristics of western Canada make it susceptible to rock falls, snow avalanches and earthquakes. Approximately 1500 earthquakes are recorded in Canada each year with potential risk to several major Canadian cities on Canada's west coast, the Ottawa-Montréal corridor and the St. Lawrence Valley (Natural Resources Canada 2004). Since older buildings (pre1970) are not subject to the seismic provisions stipulated in the 1995 National 
Building Code of Canada, the potential for severe damage due to a moderate or severe earthquake is high (Foo and Davenport 2003).

Approximately eighty percent of Canadian disasters are due to weather and weather-related hazards such as tornadoes, hurricanes, hail storms, blizzards, storm surges, ice storms and floods. Hail storms and as many as eighty tornadoes are recorded annually in southern Ontario, southeastern Québec and in the Prairie provinces of Manitoba, Saskatchewan and Alberta (McBean and Henstra 2003). Canada's Atlantic coast is susceptible to hurricanes and storm surges (Bruce 2002) and severe winter storms occur frequently across parts of the country. In the summer months, high temperatures and low humidity often create conditions ideal for wildfires that typically threaten rural settlements on the Prairies, in British Columbia, Ontario and Québec. Flooding, which is Canada's most frequently occurring disaster, affects all provinces and territories, with the highest frequency in Ontario, New Brunswick, Québec and Manitoba (Canadian Disaster Database 2004; Shrubsole et al. 2003).

A population is made more vulnerable by characteristics within the built, natural and socio-economic environment that make it susceptible to harm. An array of natural hazards highlights the likelihood that Canadians could suffer loss due to natural hazards. What makes Canada vulnerable is the concentration of its population in regions of high risk. Canada's population is concentrated in 25 census metropolitan areas (McCrea 2003), some of which are located in seismically active regions, on coastal plains or river basins that have a higher risk of flooding. For example, Vancouver, with a metropolitan population of 2.1 million, faces risks from earthquakes, tsunamis, flooding and rising sea levels. Canada's northern territories, which by comparison are sparsely populated, are less vulnerable to the same perils. Furthermore, the urban infrastructure in many Canadian communities is aging and its ability to withstand the impacts of extreme events is increasingly uncertain.

In Canada, as in other parts of the world, the tendency towards more disasters and escalating disaster costs seems inevitable. Processes such as urbanization, globalization, climate change and reliance on technologically based and interdependent infrastructure have the potential to significantly increase risks, direct and indirect costs, and the complexity of managing disasters that Canadians could face in the future - including establishing an efficient national emergency management system that encompasses mitigation, preparedness, response and recovery. Canadians experienced an array of disasters in 2003: flooding in Manitoba, British Columbia, Newfoundland and New Brunswick; destructive tornadoes and hailstorms in Manitoba and Alberta; major forest fires in Alberta, British Columbia, Manitoba and Ontario; and hurricanes in Ontario, Nova Scotia and Prince Edward Island. These events illustrate what the future could entail should the climate-change predictions of scientists materialize. Using the Canadian Disaster Database, Dore (2003) developed statistical profiles of major Canadian disasters that occurred between 1900-2000 to estimate conditional probabilities and approximate costs due to natural disasters. He concluded that Canadians can anticipate at least one geophysical disaster and 
as many as twelve hydro-meteorological disasters to occur annually with costs estimated at $\$ 29$ million $(\mathrm{CDN})$ and $\$ 1.8$ billion $(\mathrm{CDN})$ respectively. Curtailing this escalating trend begets a need to focus on reducing disaster vulnerability and to protect Canada's economic and social assets through concerted efforts in disaster mitigation.

\section{Canada's Emergency Management Framework}

The structure of Canada's emergency management system is shaped by Canada's legislative, regulatory and policy framework. The Emergency Preparedness Act (1988) outlines the emergency preparedness roles and responsibilities of federal departments and establishes the federal government's relationship with provincial and territorial governments which in turn delegate responsibility to local-level authorities. This jurisdictional relationship demands a "teamwork" approach to managing Canadian emergencies that is based on three key principles outlined below.

First, those closest to the emergency are considered best placed to provide emergency services. Local-level authorities provide the first level of response and are supported by provincial or territorial governments when a disaster exceeds locallevel capacity to cope. The Government of Canada provides support when provincial or territorial resources are exhausted, when specialized support residing in federal government institutions is required or in areas that fall exclusively under federal jurisdiction (e.g., national parks and First Nations' reservations). Notably, the vast majority of Canada's natural disasters are managed at the local or provincial level.

Second, an all-hazards approach is taken to deal with a broad range of emergencies and disasters. This generic approach encourages emergency management organizations to plan for, and reduce vulnerability from, potential adverse consequences regardless of the source, to avoid the duplication of planning efforts across the range of hazards.

Finally, a comprehensive approach integrates four interrelated, but not necessarily sequential, pillars of emergency management: mitigation, preparedness, response and recovery. These pillars are defined as:

- Mitigation - sustained measures to reduce or eliminate risks and impacts associated with natural and human-induced disasters.

- Preparedness - development of effective policies, procedures and capacities to plans for how best manage an emergency.

- Response - actions taken before, during after an emergency occurs.

- Recovery - efforts taken to repair and restore a community following an emergency.

There are two commonly held views of disaster mitigation in Canada. One that considers mitigation as occurring during all stages of the emergency management continuum (Pearce 2003) and another that views mitigation as the "upstream" cornerstone of action taken before a disaster occurs on which comprehensive 
emergency management is predicated. In terms of Canada's ongoing efforts to develop a NDMS, PSEPC's conceptualization of mitigation is pragmatic. This approach recognizes that the emergency management system operates in a continual feedback loop that is essential to improving the capacity of Canadians to manage future events. Particular emphasis is placed on the need to strengthen and integrate pre-event disaster mitigation into the broader practice of emergency management in Canada.

Until now, pre-event mitigation has been an implicit requirement despite evidence that "an ounce of prevention is worth a pound of cure." Disaster mitigation undertaken well in advance of a disaster is arguably the most critical and effective intervention for reducing risk. Its premise, unlike the other three pillars, is more closely linked to sustainable development and the ongoing everyday activities of a community. By contrast, the other three pillars are reactive and primarily seek to diminish the severity of impacts following the onset of an event or facilitate recovery efforts, rather than proactively reduce susceptibility to future harm.

Canada's current emergency management approach remains overtly responsefocussed. Recurrent natural disasters, anticipated increases in hydro-meteorological disasters due to climate variability and potential disaster-related costs to society are placing pressure on all levels of government to modernize the existing emergency management system. Placing greater emphasis on disaster risk reduction measures would help to address an "emergency-centric" orientation and reduce growing fiscal and social demands associated with response and recovery.

\section{National Consultations on Mitigation}

A first round of national consultations co-hosted by the former Emergency Preparedness Canada (predecessor to OCIPEP and now PSEPC) and the Insurance Bureau of Canada were held with stakeholders in 1998. The results of those consultations indicated that a strategy was needed to re-orient Canada's response-focussed emergency management system and to foster a culture of disaster prevention. The consultations also highlighted the need for strategic partnerships and shared responsibility among all levels of government, the private and non-governmental sectors to enable communities to work together to strengthen their resilience to the negative consequences of hazard events.

Subsequently in spring 2002, PSEPC (then OCIPEP 2002a; 2002b) used the recommendations stemming from the 1998 consultations to consult on six proposed elements of a NDMS (Appendix 1). The objectives of these consultations were to clarify the potential roles and responsibilities of all levels of government and stakeholders; learn about progress on mitigation measures developed nationally, locally or regionally; provide a forum for dialogue that would help shape policy direction; recommend priority areas for action; and model the kinds of collaborative behavior that would be required to implement a national mitigation policy. 
PSEPC embarked on a consultation process in the spring of 2002 using a publicly accessible web site, bi-lateral discussions with provincial and territorial governments, and six regional consultation workshops with stakeholders representing academia, the private and not-for-profit sectors, and industry to solicit input on disaster mitigation. The preliminary results of the regional consultation workshops and the utility of the deliberative dialogue process used to facilitate them are the focus of this paper.

\subsection{Deliberative Dialogue}

Deliberative dialogue is a structured facilitation process that engages stakeholders in a way that helps draw out important values and trade-offs associated with pursuing a particular strategic policy direction. Through a shared exploration of different perspectives, participants thoughtfully discuss a complex issue in potentially new ways that tend to break away from habitual positions or "stuck" and pre-determined solutions. Deliberative dialogue builds on participants' knowledge and experiences to find common ground from which alternative strategies or policies can be pursued (Dale 2002). In contrast to other public involvement processes, such as town-hall meetings that emphasize debate or advocacy of positions, deliberative dialogue is founded on collaboratively exploring underlying values and assumptions, sharing of collective views and building on the perspectives of others to arrive at a shared solution (Dale 2001; Mathews and McAfee 2003).

The usual application of deliberative dialogue is for citizens' groups (Mathews 1999). In this case, deliberative dialogue was used with stakeholders as a first step toward creating a long-term relationship among diverse stakeholders with ownership and commitment toward shared outcomes and responsibilities for disaster mitigation. The process brought together informed stakeholders to develop approaches for advancing disaster mitigation in Canada and to conceptualize potential roles and responsibilities for a nationally coordinated mitigation strategy.

\subsection{Deliberative Dialogue Methodology}

An "issue framing" session was held in January 2002 with a small group of selected subject-matter experts and mitigation-relevant stakeholders from government and non-governmental sectors to initiate the deliberative dialogue consultation process. During this session, participants considered various approaches to disaster mitigation as the basis for developing a deliberation (consultation) guide which provided an overview of disaster mitigation and explained the deliberative dialogue process. It also outlined three objective approaches for pursuing disaster mitigation risk management, research and empowerment that provided the "springboard" for discussion in the subsequent dialogue workshops held accross Canada.

The risk management approach supported a NDMS in which comprehensive all-hazard risk assessments would be conducted as the first step to ensuring that 
mitigation measures do not postpone or transfer risk to other areas or inadvertently increase risk(losses from other hazards. The research approach envisioned a NDMS oriented primarily towards creating and disseminating knowledge to emergency management practitioners and decision-makers. Under the empowerment approach, a NDMS would focus on establishing a supportive context by raising awareness of disaster mitigation and empowering citizens and stakeholders to undertake proactive measures within a framework that facilitates a greater degree of coordination and effective allocation of limited resources.

In May 2002, approximately 170 participants with diverse experience and views regarding emergency management, hazards research and risk management attended regional consultation workshops in Halifax, Toronto, Montréal, Winnipeg, Edmonton and Vancouver. Participants included representatives from the private sector, non-governmental organizations, academia and professional associations representing the engineering and construction industry, Canadian municipalities, First Nations groups, emergency preparedness associations, police services, urban planners and the transportation sector. Federal government and provincial officials participated as observers and information resources. Workshop participants explored each approach with the assistance of a facilitator trained in the deliberative dialogue method. The purpose of the process was to identify alternative approaches and key elements for a NDMS as well as to develop common ground that included establishing a goal, principles and scenario ideas considered essential to the development of a NDMS. The outcomes of the consultation sessions are discussed in further detail in this paper.

\subsection{Deliberative DiALOGUE AND DISASTER MITIGATION}

Deliberative dialogue corresponds suitably with the sustainable hazards mitigation paradigm. Sustainable hazards mitigation is premised on six essential components: environmental quality; quality of life; disaster resiliency; economic vitality; interand intra-generational equity; and participatory processes (Mileti 1999). The sixth component and the consensus-based approach of deliberative dialogue have similar conceptual underpinnings and intentions. In both, the involvement of local participants - people who have a stake in an issue and its outcome - is considered essential for identifying concerns and issues, generating solutions for addressing them, reaching agreement on how they could be resolved and in recommending measures to be undertaken. Both challenge stakeholders to raise first their awareness of their own assumptions and then to suspend those pre-existing biases in order to consider new ways of seeing and resolving issues that are significant to society. Stakeholders are forced to think beyond the facts and "preferred" options and consider fully the implications of the decisions being made and whether or not they represent the interests and values of society.

According to Mileti, a participatory process should be utilized for the information it generates and distributes, for the sense of community it can foster, for 
the ideas that grow out of it and for the sense of ownership that it creates. How deliberative dialogue can contribute to participatory processes within the sustainable hazards mitigation framework and the building of a culture of collaboration among stakeholders is discussed as part of the outcomes of the consultations.

\subsection{PRELIMINARY RESUlTS OF THE NDMS STAKEHOLDER CONSUltations}

The most significant result of the consultations perhaps was the realization that substantial interest and common ground exists among government and nongovernmental stakeholders. They agreed that disaster mitigation should be an emergency management priority of the Government of Canada. Overall, stakeholders were supportive of the six proposed NDMS elements and participants appreciated the use of the deliberative dialogue methodology to gather their views on disaster mitigation. Participants re-affirmed the need for Government of Canada leadership to address the existing piecemeal approach to disaster mitigation across the country by facilitating systematic coordination of these initiatives at all levels (i.e., government, private and non-governmental stakeholders). Given the multi-sectoral and interdisciplinary nature of disaster mitigation, participants advised that specific cooperative arrangements that assign responsibilities for disaster mitigation are needed. They also recommended that a NDMS should involve and empower communities to ensure that risk reduction measures do not inadvertently transfer risk to other areas or potentially increase risk from other hazards. Interdisciplinary research enhancing Canadian knowledge about hazards and disasters should be encouraged and used to inform decision-making. It was acknowledged that there is an information gap; unless a concerted effort is made to inform citizens about the risks they face and how they may be resolved, misconceptions and resistance to disaster mitigation would persist.

Participants recommended a "carrot and stick" approach using both financial incentives (e.g., tax breaks, reduced insurance premiums, grants and loans) and non-financial incentives (e.g., awards and recognition) to encourage progress on disaster mitigation. There were varied views on the use of penalties to discourage some risk-taking behavior. The insurance sector, for example, noted that individuals who choose to live in risk-prone locations should not be "rewarded" for the risk they deliberately assume. Others said that a NDMS should balance the ethical and normative values of Canadian society and seek to ensure the greatest good for the greatest number - not all individuals have a choice in the risks they assume. Evidence exists that socio-economic and cultural factors such as employment, income, education, disability and ethnicity are positively correlated with the degree of hazard exposure, individuals' risk-taking behavior and their ability to cope with hazard impacts or undertake mitigative measures (Blaikie et al. 1994; Ferrier and Haque 2003; Mileti 1999).

A range of other ideas for strengthening disaster mitigation were suggested. A NDMS should incorporate sufficient flexibility to accommodate the varying risks 


\begin{tabular}{|l|l|}
\hline \multicolumn{1}{|c|}{ Goal } & \multicolumn{1}{c|}{ Principles } \\
\hline $\begin{array}{l}\text { Protect lives while } \\
\text { maintaining sustainable and } \\
\text { resilient communities by } \\
\text { fostering disaster mitigation } \\
\text { as a way of life. }\end{array}$ & $\begin{array}{l}\text { Preserve Life - protect lives through prevention. } \\
\text { Safeguard Communities - enhance economic and social } \\
\text { viability by reducing disaster impacts. } \\
\text { Fairness - equity and consistency in implementation. } \\
\text { Sustainable - balance long-term economic, social and } \\
\text { environmental considerations. } \\
\text { Flexible - responsive to regional perspectives. } \\
\text { Shared - shared ownership and accountability through } \\
\text { partnership and collaboration. }\end{array}$ \\
\hline
\end{tabular}

Figure 1. Draft: National Disaster Mitigation Strategy - Goal and Principles.

as well as regional and local circumstances that exist across the country. Many participants strongly advocated an incremental approach to implementing a NDMS - to start modestly with what we have and what we know, and sustain the evolution of the work over the long-term. This approach would facilitate the requirement to link a NDMS to other relevant government initiatives such as reform of the federal Disaster Financial Assistance Arrangements (DFAA), climate-change adaptation, critical infrastructure protection (e.g., energy and utilities, communications and information technologies, finance, health care, food, waste and water, transportation, safety, government and manufacturing), and non-governmental initiatives. First Nations groups spoke compellingly on the need for a "seven generation" perspective linking a NDMS with a principle that underpins sustainable development - mitigation is an investment in our future and the decisions taken today should benefit, not burden, future generations.

Input from workshop participants was used to develop a vision for a NDMS, including a draft goal and set of policy principles (Figure 1) that could guide a nationally coordinated mitigation strategy and facilitate the creation of disasterresilient communities.

\subsection{UTILITY OF DELIBERATIVE DIALOGUE TO NDMS CONSULTATIONS}

Stakeholders acknowledged the value of the deliberative dialogue methodology. In particular, participants found that the method was preferable to other consultation approaches because it enabled a deeper and more meaningful exploration in the time allocated. Dialogue tended to be generative rather than argumentative or fixed in predetermined positions. In terms of the three approaches that were advanced in the deliberation guide, research was viewed as an essential tool - not a strategy in itself; risk assessment was seen as the starting point but not a complete strategy on its own; and empowerment was viewed as the over-arching approach to reach long-term 
and sustainable change. Each approach embodied important prerequisites for a NDMS, however, pursued individually, neither would provide a solid foundation for a comprehensive NDMS. Participants also noted that pursing each approach individually would perpetuate the existing piecemeal approach to mitigation.

In many ways, the deliberations supported the consensus-building thrust which is integral to the sustainable hazards mitigation paradigm. The dialogue workshops brought a significant number of key participants into the process who, until then, had not been actively engaged. By bringing together diverse and "non-traditional" stakeholders to discuss disaster mitigation policies and goals, the deliberative dialogue methodology raised the level of understanding among stakeholders and the development of new insights on disaster mitigation. Although "citizens" (i.e., individuals unaffiliated with any particular organization) were excluded from the deliberations, the significance of key stakeholders in supporting the aspirations of local communities cannot be overlooked (Fishkin 1992). The success of local-level planning and implementation of risk-reduction initiatives by community stakeholders cannot be achieved without strong leadership from all levels of government (Geis 1996; Mileti 1999; Pearce 2003). The stakeholders' deliberations on goals, policy principles and approaches to disaster mitigation generated a sound body of knowledge and assisted in the identification of priority areas for action. These results of the consultations will be influential in formulating recommendations to the Government of Canada. Provinces and territories have reviewed the outcomes of the deliberative dialogue process and have expressed general support for the thrust of the proposed NDMS vision, goal and principles.

There appears to be momentum, in part due to the 1998 and 2002 NDMS consultations and the efforts of the Canadian Natural Hazards Assessment Project (Etkin et al. 2003), to strengthen the links between the emergency management practitioner community and the hazards research community. In 2002, the deliberative dialogue consultations re-affirmed the need for knowledge generation, stronger networks of researchers and practitioners, and the creation of mechanisms to help inform the decisions of policy-makers and the actions of individual Canadians. A nationally coordinated, multi-stakeholder Canadian Risk and Hazards Network (CRHNet) has been established. The CRHNet hosted the first Canadian Symposium on disaster mitigation in November 2004 and is in the process of planning for the second in November 2005.

The deliberative dialogue process was evaluated by participants and some shortcomings were identified. The view of some participants was that the three approaches presented in the deliberation guide were not distinct. Based on that, there was some unease that the deliberative discussions were superficial as there were no "real choices" to be considered. It is acknowledged that participants' familiarity with the dialogue process and more time during the "issue framing" workshop could have aided the development of more discrete approaches that more accurately reflected the intent and values of the process. Despite this shortcoming, the stakeholder deliberations were constructive and the richness and diversity of the 
views generated are useful for directing policy and action on disaster mitigation in Canada.

It was noted that not all stakeholders were represented at the workshops, and even among those involved, not all participants became fully engaged in the deliberations despite the method's explicit goal of opening "space" and allowing all views to receive fair and equal consideration. This limitation was partly overcome by establishing parallel consultation mechanisms. For example, a publicly accessible web site augmented the deliberations to encourage the broadest representation of all views.

In the view of the majority of participants, the one-day dialogue stimulated thought-provoking discussions on disaster mitigation in Canada. A relatively small percentage felt that the process was unfamiliar and did not provide sufficient time to fully deliberate the policy and practical implications of pursuing any particular approach to disaster mitigation.

A final but key observation was that additional resources and commitment are required to understand and further develop alternative ideas raised through the workshops.

\section{Progress on Disaster Mitigation}

A NDMS is yet to be approved as of July 2005. Despite this, existing programs and new initiatives continue to provide the Government of Canada with a basis upon which to move forward on significant structural and non-structural aspects of disaster mitigation. A long-standing committee of Senior Officials Responsible for Emergency Management (SOREM), a federal/provincial/territorial advisory group and a Government of Canada Inter-departmental Mitigation Coordination Committee (IMCC) that was established by PSEPC in 2001 presently serve as the primary coordination mechanisms for governments to discuss mitigation issues. Through these bodies, mitigation-related initiatives within the Government of Canada and at the provincial and territorial levels are being identified as the basis for determining priority areas for action and future collaboration on disaster mitigation. PSEPC is also trying to find concrete ways to collaborate with non-governmental stakeholders to identify projects and initiatives that complement the government's efforts.

The process and the means by which community needs are met during recovery have a bearing on disaster mitigation. The PSEPC review of Canada's Disaster Financial Assistance Arrangements (DFAA) includes consideration of ideas relating to post-event mitigative enhancements that could augment the pre-event emphasis of a national mitigation strategy. Alignment of any DFAA modifications and a NDMS will be considered as PSEPC moves forward on both initiatives.

In addition to PSEPC's work related to disaster mitigation, other Government of Canada departments and agencies have existing programs and initiatives that lend themselves to the strategic objectives of a NDMS. For example, Environment 
Canada, through the Meteorological Service of Canada, plays a significant role in predicting and informing the public about weather-related risks. Environment Canada's completion of the National Doppler Radar Project (Environment Canada 1997) and funding support for research related to high-impact weather will provide more accurate and timely weather forecasts, potentially reducing personal injury and property damage that could result from extreme weather events.

Recent initiatives within Natural Resources Canada to implement a Natural Hazards Action Plan, and to develop detailed hazard and risk assessments along with the proposed development of a Canadian Disaster Management Information System, contribute to disaster mitigation planning and emergency response, potentially diminishing risks from earthquakes, tsunamis and landslides. Through the Climate Change Impacts and Adaptation Directorate, Natural Resources Canada is also providing leadership for Canadian efforts to anticipate and plan for the impacts of climate change relating to extreme weather events.

The Canadian government is investing substantially in the renewal of Canada's public infrastructure through the Canada Strategic Infrastructure Fund (CSIF). The CSIF provides a unique partnership opportunity for the federal, provincial and territorial, and municipal governments to reduce disaster vulnerability and to support the development of disaster-resilient communities by incorporating risk-reduction measures during the design, building and refurbishing of major infrastructure. The National Research Council has a mandate to develop and update Canada's national building codes (providing another area linked to the proposed NDMS goal and principles) which may be further enhanced to strengthen national efforts in disaster mitigation.

PSEPC also promotes a "levers and lenses" approach that allows it to strategically influence and coordinate disaster risk reduction efforts through horizontal collaboration with key federal departments. In the case of major infrastructure initiatives, for example, the use of an analytical "mitigation lens" would encourage better foresight at an early stage to incorporate risk-reduction measures when developing or upgrading major public infrastructure. Such steps would help encourage more effective use of resources and adoption of development policies that are aligned with the objectives of disaster mitigation. PSEPC's success in establishing linkages with other federal initiatives was reflected in an April 2003 announcement by the Government of Canada (concerning the Canada Strategic Infrastructure Fund) and the Government of Manitoba to cost-share the first stages of a major expansion of the Red River Floodway which will further protect the City of Winnipeg from devastating floods. The current "levers and lenses" approach stems from advice advanced during the spring 2002 round of disaster mitigation consultations and is aimed at maximizing the use of existing limited resources, programs and initiatives of other federal and national agencies.

Provincial and territorial governments have embarked on important initiatives that enhance disaster mitigation. In the Northwest Territories, the government has initiated an innovative forest fire protection program that involves community 
participation to construct and maintain fire breaks and reduce fuel loads by planting deciduous trees with low flammability. Québec's Civil Protection Act of December 2000 and Ontario's Emergency Readiness Act of November 2002 (both of which require municipalities to undertake hazard identification and risk assessment, and adopt preventive measures to reduce disaster vulnerability) are further examples of forward-looking provincial measures that help strengthen Canada's emergency management system through disaster mitigation.

In the summer of 2003, the Canadian Natural Hazards Assessment Project, jointly funded by PSEPC, the Meteorological Service of Canada and the Institute for Catastrophic Loss Reduction, published Canada's first comprehensive assessment on the state and nature of knowledge about Canadian hazards and disasters. The joint funding approach and the voluntary technical input provided by Canadian hazards research experts and emergency management practitioners are illustrative of new partnerships that are generating knowledge, informing the public and supporting policy-makers and emergency management practitioners with improved risk-management information.

\section{Challenges}

Thus far, the process of developing Canada's NDMS has highlighted a number of areas to be addressed. Governance issues, for example, could be complex to address depending on the eventual scope of a NDMS. What should be the proper balance and type of leadership on the part of the federal, provincial and territorial, and municipal governments? Provincial and territorial emergency management organizations (EMOs) have the legislative authority to support a range of emergency management efforts, but current laws do not necessarily position EMOs to influence action on pre-event mitigative measures. For example, the enforcement of building codes or land-use regulations are delegated to municipal authorities or viewed by provincial ministries as non-emergency management responsibilities. The pressing issue is not whether, but how, to best integrate disaster mitigation into the evolving emergency management framework. Jurisdictions are unlikely to welcome any increased responsibility related to disaster-mitigation planning without corresponding increases in resources. Fiscal pressures have led to further questions about how municipalities and other stakeholders could be involved in the decision-making process and, in particular, whether a NDMS should be implemented on a voluntary basis, through legislation, or by using a "bottom-up" or "top-down" approach.

Determining funding requirements for a NDMS remains a fundamental and ongoing challenge. No decisions on the scale of investment, if any, for a NDMS have been made at the time of writing. Some stakeholders noted during consultations that a credible NDMS would need to be sufficiently funded upfront to strengthen capacity in identified areas of significant weakness. Other stakeholders noted that obtaining additional resources was important, although significant initial progress 
could be made with modest incremental resources. Questions were also raised on how to estimate new resource needs for disaster mitigation. For example, should funding mechanisms be separate or linked to existing programs? How should costsharing with the private and non-governmental sector be explored? There were mixed views on these questions, particularly on whether to link a NDMS to resources available through the CSIF. In the absence of nationally consistent costbenefit methodologies, quantifying disaster costs and making the business-case for additional resources to support disaster-mitigation efforts remains an ongoing challenge.

Terrorist events (e.g., September 11, 2001) and the new security environment, animal diseases (e.g., Bovine Spongiform Encephalopathy), human diseases (e.g., Severe Acute Respiratory Syndrome) and a widespread power failure (August 2003) that affected Ontario and parts of the United States have demanded immediate attention and resources from affected sectors across all levels of government. While the social and economic costs associated with these disasters have once again highlighted the need to take action before disaster strikes, these compelling and urgent priorities for emergency response may have drawn the focus of decisionmakers and practitioners away from the NDMS development process.

\section{Future Direction on Disaster Mitigation}

With the creation of PSEPC in December 2003, the Government of Canada signaled its intent to renew Canada's emergency management system through a new "whole-of-government" approach to public safety and emergency preparedness. The new approach places clear emphasis on the need for a robust and comprehensive emergency management system. With respect to disaster mitigation, building a NDMS is an evolutionary process integral to the enhancement of the current emergency management system. A NDMS may best be initiated through existing programs and resources at the outset, and be built up as more resources become available. Future areas of focus for a NDMS should build on the six proposed elements (Figure 2). Targeted initiatives would be implemented by all levels of government, private and non-governmental sectors to influence public attitudes pertaining to risk reduction. Efforts could be directed toward ensuring that a NDMS is underpinned by high-quality research and technical expertise, and takes advantage of new technologies to improve risk-management decisions and disseminate knowledge about hazards.

It is envisaged that a NDMS would encourage cost-shared efforts and partnered initiatives to ensure that mitigation activities are implemented and monitored at the most appropriate level. The Government of Canada will continue to promote a "whole-of-government" approach to disaster mitigation. Both structural and nonstructural mitigation approaches will be encouraged using "levers and lenses" to incorporate risk-reduction criteria in future infrastructure projects. 


\begin{tabular}{|l|l|}
\hline \multicolumn{1}{|c|}{ Element } & \multicolumn{1}{|c|}{ Description } \\
\hline $\begin{array}{l}\text { Leadership and } \\
\text { Coordination }\end{array}$ & $\begin{array}{l}\text { Coordination of disaster mitigation activities occurring at all } \\
\text { levels of government, the private sector, non-government } \\
\text { organizations and communities to ensure an integrated } \\
\text { approach to managing mitigation. }\end{array}$ \\
\hline $\begin{array}{l}\text { Partnership and Shared } \\
\text { Responsibility }\end{array}$ & $\begin{array}{l}\text { Encouraging partnerships among all levels of government, } \\
\text { professional groups and academia, and the private and } \\
\text { voluntary sectors to develop consensus on disaster- } \\
\text { mitigation matters. }\end{array}$ \\
\hline $\begin{array}{l}\text { Hazard Identification and } \\
\text { Risk Assessment }\end{array}$ & $\begin{array}{l}\text { Ensuring that measures to reduce the impact of probable } \\
\text { disasters are taken based on sound hazard identification and } \\
\text { risk assessment. }\end{array}$ \\
\hline $\begin{array}{l}\text { Research, Information } \\
\text { Dissemination and }\end{array}$ & $\begin{array}{l}\text { Ensuring that research provides current, accessible, } \\
\text { coordinated and complementary tools that assist informed } \\
\text { decision-making on disaster mitigation. }\end{array}$ \\
\hline $\begin{array}{l}\text { Public Awareness, } \\
\text { Training and Education }\end{array}$ & $\begin{array}{l}\text { Ensuring that governments and the public perceive and } \\
\text { understand the risks and the range of contingencies for } \\
\text { reducing the risk or impact. }\end{array}$ \\
\hline Incentives and Resources & $\begin{array}{l}\text { Incentives for disaster mitigation are required if mitigation is } \\
\text { to become a consideration for all stakeholders. }\end{array}$ \\
\hline
\end{tabular}

Figure 2. Proposed elements of a national disaster mitigation strategy.

\section{Conclusion}

Stakeholders strongly supported the concept of a NDMS as part of the need to create a robust national emergency management system. They agreed that mitigation would be a wise investment in Canada's future. The existing commitment is supported by the fact that governments at all levels continue to make meaningful, albeit modest, investments in disaster mitigation in the absence of a fully-developed NDMS. An overarching framework for disaster mitigation would address the current shortcomings associated with a piecemeal approach to mitigation. Greater attention to mitigation would also strengthen the broader emergency management framework in Canada.

While progress on disaster mitigation has been made during the last 3 years now, more work is required to collate, quantify and assess mitigative capacities across the country and help build a compelling business case for a NDMS. The right mix of incentives and "disincentives," balanced legislation, regulations and policies could augment local-level responsibility and investment in disaster mitigation. Participatory attributes of deliberative dialogue are relevant and complementary to the prevailing emergency/disaster management paradigm because they bring into focus essential knowledge and expertise to inform and support effective decision-making.

Dialogue with key stakeholders has advanced the determination of a common vision, goal and set of principles for a NDMS. The potential roles of governments and stakeholders are also taking shape. The motivation for finding effective mitigation solutions that will help renew Canada's national emergency management system is a society better able to withstand and manage the consequences of disasters. 


\section{Acknowledgments}

The author wishes to acknowledge PSEPC colleagues Peter Hill, Brian Klotz and Michael Holmes for their contribution to this paper.

\section{References}

Blaikie, P., Canon, T., Davis, I. and Wisner, B.: 1994, At Risk: Natural Hazards, People's Vulnerability, and Disasters, Routledge, London.

Bruce, J.: 2002, Consequence Analysis of Storm Surge in Charlottetown, Prince Edward Island, Public Safety and Emergency Preparedness Canada, Ottawa, Canada.

Canadian Disaster Database: 2004, Public Safety and Emergency Preparedness Canada. Available at: www.ocipep-bpiepc.gc.ca/disaster/default.asp.

Dale, J.: 2001, Opening Dialogue, Opening Minds: Encouraging Citizen Engagement, Caledon Institute for Social Policy, pp. 1-8.

Dale, J.: 2002, Public Dialogue: Bridging the Gap Between Knowledge and Wisdom, Master's Thesis, Master of Management for National Voluntary Sector Leaders, McGill-McConnel Program.

Dore, M.: 2003, 'Forecasting the conditional probabilities of natural disasters in Canada as a guide for disaster preparedness', Natural Hazards 28, 249-269.

Geis, D.: 1996, 'Creating sustainable and disaster resilient communities', Working Paper, The Aspen Global Change Institute, Aspen, Colorado. Available at: www.sustainable.doe. gov/articles/CREATING.shtml.

Ferrier, N. and Haque, E.: 2003, 'Hazard risk assessment methodology for emergency managers: A standardized framework for application', Natural Hazards 28, 271-290.

Fishkin, J.S.: 1992, The Dialogue of Justice: Toward a Self Reflective Society, Yale University.

Foo, S. and Davenport, A.: 2003, 'Seismic hazard mitigation for buildings', Natural Hazards 28, 517-536.

Environment Canada: 1997, 'Improving public safety with Canada's Doppler Radar Network' . Available at: www.ec.gc.ca/press/dopp_b_e.htm.

Etkin, D., Haque, C.E. and Brooks, G.R. (eds.): 2003, 'An assessment of natural hazards and disasters in Canada', Natural Hazards 28(2-3), 211-593.

McBean, G. and Henstra, D.: 2003, 'Climate change, natural hazards and cities', Institute for Catastrophic Loss Reduction Research Paper Series 31, Toronto.

McCrea, J.: 2003, Identifying Determinants of Urban of Health: A Review and Assessment of the Literature, Prepared for Health Canada.

Mathews, D.: 1999, 'Deliberation as seen by citizens who deliberate', Kettering Review 17(1), 4552.

Mathews, D. and McAfee, N.: 2003, Making Decisions Together: The Power of Public Deliberation, Kettering Foundation, Dayton, Ohio. Available at: www.kettering.org/Foundation_ Publications/Publication_List/publication_list.html\#Public\%20Choice\%20Pub.

Mileti, D.: 1999, Disasters by Design - A Re-Assessment of Natural Hazards in the United States, Joseph Henry Press.

Natural Resources Canada: 2004, Earthquake Canada: Major Earthquakes in Canada-20th Century. Available at: www.seismo.nrcan.gc.ca/major_eq/majoreq_e.php

Office of Critical Infrastructure Protection and Emergency Preparedness (OCIPEP): 2002a, Discussion paper, Towards a National Disaster Mitigation Strategy, Government of Canada. 
Office of Critical Infrastructure Protection and Emergency Preparedness (OCIPEP): 2002b, National Disaster Mitigation Strategy, Towards a Canadian Approach, A Guide for Deliberation, Minister of Public Works and Government Services, Canada.

Pearce, L.: 2003, 'Disaster management and community planning, and public participation: How to achieve sustainable hazards mitigation', Natural Hazards 28, 211-228.

Shrubsole, D., Brooks, G., Halliday, R., Haque, E., Kumar, A. and La Croix, J.: 2003, An Assessment of Flood Risk Management in Canada, Institute for Catastrophic Loss Reduction, Paper series No. 28. 